\title{
Increase in SARS-CoV-2 RBD-specific IgA and IgG Antibodies in Breast Milk from Lactating Women Following the COVID-19 Booster Vaccination
}

\author{
Andrea M. Henle ${ }^{1 *}$ \\ ${ }^{1}$ Biology Department, Carthage College, 2001 Alford Park Drive, Kenosha, WI, 53140 USA \\ *Corresponding author
}

\begin{abstract}
The CDC recommended a booster dose of the Pfizer-BioNTech Comirnaty (BNT162b2) COVID-19 mRNA vaccine in September 2021 for high-risk individuals. Pregnant and high-risk lactating women were encouraged to receive the booster to obtain potential prolonged protection for themselves and their infants. This study investigated the ability of the booster vaccine to increase IgA and IgG antibodies specific to the receptor binding domain (RBD) of the SARS-CoV2 spike protein in breast milk compared to levels pre-booster. We found a significant increase in both anti-RBD-specific IgA and IgG antibodies in breast milk following the Pfizer-BioNTech booster and this increase was present in the majority of participants at the study endpoint (60 days post-booster). These results suggest the booster enhances SARS-CoV-2 specific immunity in human breast milk, which may be protective for infants.
\end{abstract}




\section{Background}

The CDC recommended a booster dose of the Pfizer-BioNTech Comirnaty (BNT162b2) COVID-19 mRNA vaccine in September 2021 for people ages 65 and older, adults with underlying health conditions, and frontline workers ${ }^{1}$. Pregnant and lactating women in these groups were advised to consider the booster for potential prolonged protection for themselves and their infants. Previous studies reported an increase in severe acute respiratory syndrome coronavirus 2 (SARS-CoV-2)-specific IgG and IgA immunity in breast milk following the first and second doses of the Pfizer-BioNTech vaccine $e^{2-5}$. This study investigated the ability of the booster vaccine to increase $\lg A$ and $\operatorname{Ig} G$ antibodies specific to the receptor binding domain (RBD) of the SARS-CoV-2 spike protein in breast milk compared to levels pre-booster.

\section{Methods}

Participants were prospectively recruited through social media posts in academic and regional mom groups. Participants needed to be lactating, must have received the standard two-dose Pfizer-BioNTech vaccination series at least 6-months prior, had no known diagnosis or suspected infection for COVID-19, and provide written informed consent. Changes in health status were monitored with a post-study survey. The study was approved by the Institutional Review Board at Carthage College (IRB\# 1817816-1).

Participants collected milk at 30-days and 1-day pre-booster, and 7-, 14-, 21-, 30-, 45-, and 60days post-booster. $200 \mu \mathrm{l}$ of blood was collected from each participant in January 2022 ( $\geq 60$ 
days post-booster). Samples were stored at $-20^{\circ} \mathrm{C}$ until analysis. The negative control was milk from July 2019.

Anti-RBD IgA and IgG levels were assessed via enzyme-linked immunosorbent assay (ELISA)

(Ancell Corp.). Blood from a COVID-19 positive patient was serially-diluted into negative control milk to generate a standard curve. IgA and IgG levels were converted to units/ml. A one-way ANOVA with Dunnett's multiple comparisons test was used to determine differences between the mean levels of IgA and IgG pre-booster (day -1) to all other time points. The significance threshold was $p<0.05$. Analyses were performed with Prism 7.

\section{Results}

12 women provided a total of 87 milk samples (Table). Women were a mean (SD) age of 35.45 (4.17) years and infants 3.58 (1.8) months at the time of booster. The mean (SD) time between the second dose of the vaccine and the booster was $7.01(0.62)$ months. $91.67 \%$ of women reported a vaccine-related adverse event after the booster, with injection site soreness the most frequent event (75\%). $58.33 \%$ of women had anti-RBD-specific IgA antibodies and $100 \%$ of women had anti-RBD-specific IgG antibodies in their blood at $\geq 60$ days post-booster.

Anti-RBD-specific IgA antibodies in milk significantly increased by day $7 ; 71.43 \%$ of participants had an increased level at day 7 compared to pre-booster (day -1) (Figure). At day 60, 50\% of participants had significantly increased RBD-specific IgA antibodies. Anti-RBD-specific IgG antibodies in milk significantly increased by day $14 ; 90 \%$ of participants had an increased level 
at day 14 compared to pre-booster (day -1). The anti-RBD-specific IgG levels remained significantly increased compared to the pre-booster level at 21 days, 45 days, and 60 days.

77.78\%, 72.73\%, 83.33\% of participants had significantly increased IgG levels at 21, 45, and 60 days, respectively. On an individual level, $11 / 12$ participants $(91.67 \%)$ had a significant increase in RBD-specific IgA levels at one or more time points post-booster, whereas $12 / 12$ (100\%) had a significant increase in RBD-specific IgG at $\geq 2$ time points post-booster (individual data not shown).

\section{Discussion}

We found a significant increase in anti-RBD-specific IgA and IgG antibodies in breast milk following the Pfizer-BioNTech booster. Other studies have reported high IgG levels in breast milk following the standard two-dose vaccination against SARS-CoV- $2^{2-4}$, and we observe a similar effect post-booster. Previous research suggests IgG in breast milk may be important for protection against viral infections ${ }^{6,7}$. Another study ${ }^{8}$ reported that the $\lg A$ and $\lg G$ antibodies induced following COVID-19 infection are capable of neutralizing SARS-CoV-2 in vitro, which suggests that the immunoglobulins induced following the booster vaccination may potentially offer enhanced protection for both the mother and infant.

\section{Limitations}

The sample size was limited and should be expanded to include participants from other races and ethnicities and an age range more representative of the average child-bearing population. No functional assays were performed to assess the protective activity of the immunoglobulins. 
medRxiv preprint doi: https://doi.org/10.1101/2022.02.23.22271414; this version posted February 24, 2022. The copyright holder for this preprint (which was not certified by peer review) is the author/funder, who has granted medRxiv a license to display the preprint in perpetuity.

It is made available under a CC-BY-NC-ND 4.0 International license .

This study did not assess immunoglobulins following a booster with the Moderna vaccine or a

mix-and-match (Pfizer-BioNTech, Moderna, or Johnson \& Johnson) approach to doses 1, 2, and

the booster. Participants were not tested for SARS-CoV-2 via real-time reverse transcriptase

polymerase chain reaction (RT-PCR) as part of this study. However, no participants reported

any known exposures to COVID-19 or any positive at-home or RT-PCR test results.

\section{References}

1. Coronavirus Disease 2019. Centers for Disease Control and Prevention. Published September 27, 2021. Accessed February 22, 2022.

https://www.cdc.gov/media/releases/2021/p0924-booster-recommendations-.html

2. Baird JK, Jensen SM, Urba WJ, Fox BA, Baird JR. SARS-CoV-2 Antibodies Detected in Mother's Milk Post-Vaccination. J Hum Lact. 2021;37(3):492-498.

doi:10.1177/08903344211030168

3. Perl SH, Uzan-Yulzari A, Klainer $\mathrm{H}$, et al. SARS-CoV-2-Specific Antibodies in Breast Milk After COVID-19 Vaccination of Breastfeeding Women. JAMA. 2021;325(19):2013-2014.

doi:10.1001/jama.2021.5782

4. Low JM, Gu Y, Ng MSF, et al. Codominant IgG and IgA expression with minimal vaccine mRNA in milk of BNT162b2 vaccinees. NPJ Vaccines. 2021;6:105. doi:10.1038/s41541-02100370-z

5. Valcarce V, Stafford LS, Neu J, et al. Detection of SARS-CoV-2-Specific IgA in the Human Milk of COVID-19 Vaccinated Lactating Health Care Workers. Breastfeed Med. 2021;16(12):10041009. doi:10.1089/bfm.2021.0122

6. Mazur NI, Horsley NM, Englund JA, et al. Breast Milk Prefusion F Immunoglobulin $\mathrm{G}$ as a Correlate of Protection Against Respiratory Syncytial Virus Acute Respiratory Illness. J Infect Dis. 2019;219(1):59-67. doi:10.1093/infdis/jiy477

7. Fouda GG, Yates NL, Pollara J, et al. HIV-specific functional antibody responses in breast milk mirror those in plasma and are primarily mediated by IgG antibodies. J Virol. 2011;85(18):9555-9567. doi:10.1128/JVI.05174-11

8. Pace RM, Williams JE, Järvinen KM, et al. Characterization of SARS-CoV-2 RNA, Antibodies, and Neutralizing Capacity in Milk Produced by Women with COVID-19. mBio.

2021;12(1):e03192-20. doi:10.1128/mBio.03192-20 
medRxiv preprint doi: https://doi.org/10.1101/2022.02.23.22271414; this version posted February 24, 2022. The copyright holder for this preprint (which was not certified by peer review) is the author/funder, who has granted medRxiv a license to display the preprint in perpetuity. It is made available under a CC-BY-NC-ND 4.0 International license.

Additional Contributions: We thank Joan Donner and Paul Everson (Ancell Corp.) for technical assistance with the ELISA assays. Neither were compensated for their contributions. 


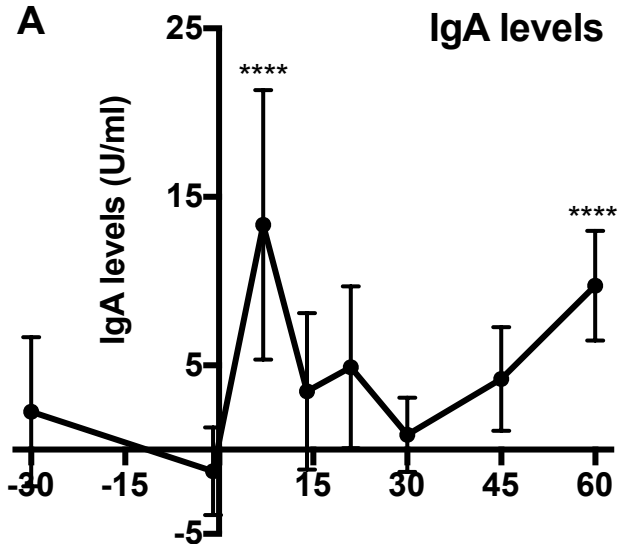

Time from booster, days

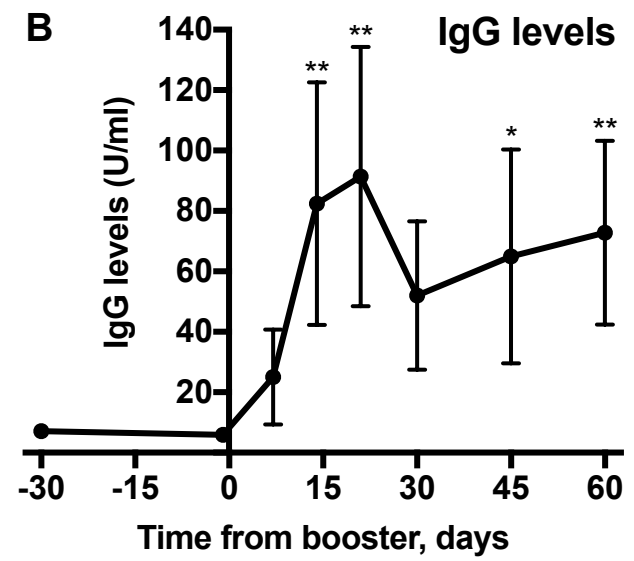

Figure. Levels of anti-RBD-specific IgA and IgG in Human Breast Milk Following the PfizerBioNTech Booster Vaccine. Each time point is compared to the pre-booster levels of $(A) \lg A$ and (B) IgG at day $-1 .{ }^{* *}$ indicates $p<0.05,{ }^{* *} p<0.01, * * * * p \leq 0.0001$. Data points represent means; error bars, $95 \% \mathrm{Cls}$. 
Table. Participant Characteristics

\begin{tabular}{|c|c|c|}
\hline & No. (\%) & \\
\hline Study participants, No. & 12 & \\
\hline \multicolumn{3}{|l|}{ Maternal features } \\
\hline White, not Hispanic or Latino or Spanish origin & $12(100)$ & \\
\hline Maternal Age, mean (SD), y & $35.45(4.17)$ & \\
\hline Weight, mean (SD), kg & $83.50(23.57)$ & \\
\hline Height, mean (SD), m & $1.654(0.075)$ & \\
\hline Asthma & $1(8)$ & \\
\hline Antibiotic use in last six months & $2(17)$ & \\
\hline \multicolumn{3}{|l|}{ Pregnancy features } \\
\hline Gestational Diabetes & $5(42)$ & \\
\hline Hypertension & $2(17)$ & \\
\hline Gravidity, mean (SD) & $2.75(1.42)$ & \\
\hline Birth week, mean (SD) & $39.30(0.74)$ & \\
\hline First vaccine during pregnancy & $8(67)$ & \\
\hline Pregnancy week at first Pfizer dose, mean (SD) & $22.02(7.21)$ & \\
\hline Pregnancy week at second Pfizer dose, mean (SD) & $25.02(7.31)$ & \\
\hline Infant age when mother received booster, mean (SD), mo & $3.58(1.8)$ & \\
\hline First vaccine after pregnancy & $4(33)$ & \\
\hline Infant age when mother received booster, mean (SD), mo & $10.84(0.64)$ & \\
\hline Time between 2nd vaccine dose and booster, mean (SD), mo & $7.01(0.62)$ & \\
\hline Booster vaccine adverse effects & $11(92)$ & \\
\hline Injection site soreness & $9(75)$ & \\
\hline Injection site rash & $1(8)$ & \\
\hline Injection site swelling & $3(25)$ & \\
\hline Injection site redness & $4(33)$ & \\
\hline Headache & $2(17)$ & \\
\hline Muscle or body aches & $4(33)$ & \\
\hline Joint pain & $3(25)$ & \\
\hline Fatigue or tiredness & $4(33)$ & \\
\hline Fever & $3(25)$ & \\
\hline Chills & $5(42)$ & \\
\hline Syncope & $1(8)$ & \\
\hline IgA positive serum at day $\geq 60$ & $7(58)$ & \\
\hline IgG positive serum at day $\geq 60$ & $12(100)$ & \\
\hline Participants represented at each time point, No. (\%) & IgA analysis & IgG analysis \\
\hline Day -30 & $8(67)$ & $8(67)$ \\
\hline Day -1 & $10(83)$ & $10(83)$ \\
\hline Day 7 & $7(58)$ & $9(75)$ \\
\hline Day 14 & $10(83)$ & $10(83)$ \\
\hline Day 21 & $9(75)$ & $9(75)$ \\
\hline Day 30 & $11(92)$ & $11(92)$ \\
\hline Day 45 & $11(92)$ & $11(92)$ \\
\hline Day 60 & $12(100)$ & $12(100)$ \\
\hline
\end{tabular}

